\title{
Geological uncertainty and geophysical inversion
}

\author{
Jessell, M. ${ }^{1,2,6}$, Aillères, ${ }^{2}{ }^{2}$, de Kemp, E. ${ }^{3}$, Lindsay, M. ${ }^{1}$, Wellmann, $\mathrm{F}^{3}$, Hillier, M. ${ }^{4}$, Laurent, G. ${ }^{2}$, \\ Charmichael, T. ${ }^{2}$, and Martin, R. ${ }^{5}$ \\ ${ }^{1}$ Centre for Exploration Targeting, University of Western Australia, 35 Stirling Highway, Crawley, WA, 6009, Australia \\ ${ }^{2}$ Monash University, PO Box 28E, Victoria, Australia \\ ${ }^{3}$ Graduate School AICES, RWTH Aachen University, Aachen, Germany \\ ${ }^{4}$ Geological Survey of Canada, Ottawa, Canada \\ ${ }^{5}$ CNRS, UMR 5563, GET, 14 Av. Edouard Belin, 31400 Toulouse, France \\ ${ }^{6}$ Institut de Recherche pour le Développement, UR 234, GET, 14 Av. Edouard Belin, 31400 Toulouse, France
}

Existing 3D geological systems are well adapted to high datadensity environments, such as at the mine scale where abundant drill core exists, or in basins where 3D seismic provides stratigraphic constraints, but are poorly adapted to regional geological problems. There are three areas where improvements in the 3D workflow need to be made: in the handling of uncertainty; in the model building algorithms themselves; and in the interface with geophysical inversion.

All 3D models are under-constrained, and at the regional scale this is especially critical for choosing modelling strategies. The practice of only producing a single model ignores the huge uncertainties that underlie model-building processes, and underpins the difficulty in providing meaningful information to end-users about the inh erent risk involved in applying the model to solve geological problems. Future studies need to recognize this and focus on the characterization of model uncertainty, spatially and in terms of geological features, and produce plausible model suites, rather than single models with unknown validity [Jessell, MW and Ailleres, L. and de Kemp, E.A., 2010, Wellmann, J.F.and Horowitz, F.G.and Schill, E. and Regenauer-Lieb, K., 2010, Lindsay, M.D. and Ailleres, L., Jessell and M.W., de Kemp, E.A. and Betts, P.G., 2012].

The most promising systems for understanding uncertainty use implicit algorithms because they allow the inclu sion of some geological knowledge, for example, age relationships of faults and onlap-offlap relationships [Calcagno, P. and Chilès, J. P. and Courrioux, G. and Guillen, A., 2008]. Unfortunately, existing implicit algorithms belie their origins as basin or mine modelling systems because they lack inclusion of normal structural criteria, such as cleavages, lineations, and recognition of poly-deformation, all of which are primary tools for the fi eld geologist that is making geological maps in structurally complex areas. One area of future research will be to establish generalized structural geological rules that can be built into the modelling process.

Topology - the connectivity between different elements of a model - is often of particular interest in geological modelling. For example, topology is critical when evaluating potential for fluid flow along faults or fluid migration through porous units, or for estimation of electrical conductivity.

Topology also has the potential to constrain or eliminate parts of the model sets generated by Monte Carlo simulations; given that topological constraints (e.g. age relationships, regional stratigraphy) are often well established prior to geo- logical modelling. Analysis of uncertainty in topology could provide a powerful enhancement to existing Monte Carlo methods.

Finally, and this probably represents the biggest challenge, there is the need for geological meaning to be maintained during the model building processes. Current data flows consist of the construction of complex 3D geological models that incorporate geological and geophysical data as well as the prior experience of the modeller, via their interpretation choices. These inputs are used to create a geometric model, which is then transformed into a petrophysical model prior to geophysical inversion. All of the underlying geological rules are then ignored during the geophysical inversion process. Examples exist that demonstrate that the loss of geological meaning between geological and geophysical modelling can be at least partially overcome by increased use of uncertainty characteristics in the workflow.

\section{References}

Calcagno, P. and Chilès, J. P. and Courrioux, G. and Guillen, A. Geological modelling from fi eld data and geological knowledge: Part I. Modelling method coupling 3D potentialfi eld interpolation and geological rules., 2008. (Cited page 1)

Jessell, MW and Ailleres, L. and de Kemp, E.A. Towards an integrated inversion of geoscientific data: What price of geology?, 2010. (Cited page 1)

Lindsay, M.D. and Ailleres, L., Jessell and M.W., de Kemp, E.A. and Betts, P.G. Locating and quantifying geological uncertainty in three-dimensional models: Analysis of the Gippsland Basin, southeastern Australia., 2012. (Cited page 1)

Wellmann, J.F.and Horowitz, F.G.and Schill, E. and Regenauer-Lieb, K. Towards incorporating uncertainty of structural data in 3D geological inversion., 2010. (Cited page 1) 